\title{
UU rings
}

\section{GRIGORE CĂLUGĂREANU}

\section{ABSTRACT.}

A new class of rings is studied: rings all whose units are sums $1+n$, for a suitable nilpotent element $n$. These are called UU rings.

\section{REFERENCES}

[1] Breaz, S., Călugăreanu, G., Danchev, P. and Micu, T., Nil-clean matrix rings, Linear Algebra Appl., 439 (2013), No. 10, 3115-3119

[2] Diesl, A. J., Classes of strongly clean rings, PhD Thesis. University of California, Berkeley, 2006

[3] Diesl, A. J., Nil clean rings, J. of Algebra, 383 (2013), 197-211

[4] Fuchs, L., Infinite Abelian Groups, vol. 1, 2, Academic Press (1970-73)

[5] Henriksen, M., Two classes of rings generated by their units, J. Algebra, 31 (1974), 182-193

[6] Krylov, P., Mikhalev, A. and Tuganbaev, A., Endomorphism Rings of Abelian Groups, Kluwer Academic Publishers, 2003

[7] Lam, T. Y. A first course in noncommutative rings, vol. 131, Graduate Texts in Mathematics, Springer-Verlag, New York, second edition, 2001

[8] Macdonald, I. G., Symmetric functions and Hall polynomials,Oxford Mathematical Monographs, The Clarendon Press Oxford University Press, New York, second edition, 1995

[9] Nicholson, W. K. and Zhou, Y., Rings in which elements are uniquely the sum of an idempotent and a unit, Glasg. Math. J., 46 (2004), No. 2, 227-236

DePARTMENT OF MATHEMATics

BABEŞ BOLYAI UNIVERSITY

KOGALNICEANU 1, 400080 CluJ-NAPOCA, ROMANIA

E-mail address: calu@math.ubbcluj.ro

Received: 27.10.2013; In revised form: 28.04.2014; Accepted: 30.04.2014

2010 Mathematics Subject Classification. 16U60, 16U99.

Key words and phrases. Unit, nilpotent, nil-clean, UU ring. 